\title{
Correlates of Older Adults' E-Health Information-Seeking Behaviors
}

\author{
Sara Pourrazavi ${ }^{a, b}$ Kamiar Kouzekanani ${ }^{c}$ Mohammad Asghari Jafarabadi ${ }^{d}$ \\ Shahrzad Bazargan-Hejazi ${ }^{\mathrm{e}}$ Mina Hashemiparast ${ }^{f}$ Hamid Allahverdipour $^{\mathrm{a}, \mathrm{b}}$

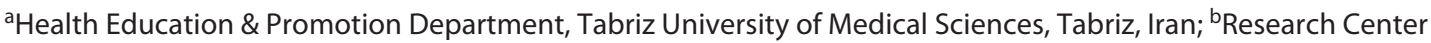 \\ of Psychiatry and Behavioral Sciences, Tabriz University of Medical Sciences, Tabriz, Iran; 'College of Education \& \\ Human Development, TAMUCC, Corpus Christi, TX, USA; dDepartment of Statistics and Epidemiology, Faculty of \\ Health, Tabriz University of Medical Sciences, Tabriz, Iran; 'Department of Psychiatry, Charles R. Drew University of

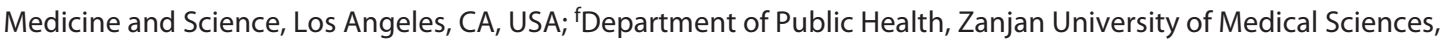 \\ Zanjan, Iran
}

\section{Keywords}

Information seeking · Internet - Older adults · Online health . E-health information $\cdot$ COVID-19

\begin{abstract}
Introduction: The Internet is an important source for health information and a medium for older adults' empowerment in health decision-making and self-caring. Therefore, we aimed to identify the potential motivators and probable barriers of e-health information-seeking behaviors (e-HISB) among older Iranian adults. Methods: A cross-sectional study assessed the usefulness of self-efficacy, perceived encouragement, positive attitude toward e-HISB, perceived usefulness, challenges of being visited by physicians, and perceived barriers in predicting e-HISB in a sample of 320 older adults in Tabriz, Iran. Results: The self-efficacy for online information seeking, positive attitude toward e-HISB, and perceived usefulness increased the odds of e-HISB by $12.00 \%$, $24.00 \%$, and $15.00 \%$, respectively. In addition, e-health literacy, conflicting information, distrust of online information, and web designs that were not senior-friendly were the ma-
\end{abstract}

jor barriers to e-HISB. Discussion/Conclusion: The theoretical and practical implications of the motivators and barriers of e-HISB can be instrumental in designing and executing programs aimed at improving e-health literacy among older adults especially during the COVID-19 pandemic.

(c) 2022 S. Karger AG, Basel

\section{Introduction}

Population aging may increase the demand for and raise the costs of integrated health care services for older adults [1]. Indeed, aging and age-related changes may result in multiple and chronic health problems among older people [1], affecting their lives from diet management to ensuring proper drug administration at the right time [2]. It is postulated that having a greater understanding of health conditions would help older adults to better manage their health problems [3], by playing an active role in managing their own wellness.

The Internet plays an influential role in providing educational content and opportunities for older adults [4] 
because it is an easily accessed provider of information that can replace printed sources [5]. Useful features of the Internet make it a popular source of health information among older adults; for example, providing access to health-related information or services, obtaining answers to health-related issues, filling and refilling medications, and communicating with health care providers [6-9]. Additionally, e-health information enables individuals to participate consciously in health decisions and to better understand the information provided by health care providers [5]. Due to COVID-19, we are encouraged to observe social/physical distancing; consequently, e-health information can be instrumental in reducing anxiety, improving mental health status, and facilitating the understanding of various public health reports [10].

According to the literature, various individual, cognitive, and social factors can predict e-health informationseeking behaviors (e-HISB). For example, studies have shown that being a woman, being younger, and having higher income and education are associated with using the Internet to search for health-related information [11, 12]. In addition, research has demonstrated the predictive role of self-efficacy, positive attitudes toward online information, perceived usefulness, and subjective norms for e-HISB [13-16].

Because older adults are less inclined to use e-HISB [17], identifying the factors that may influence older adults' intention to use e-HISB is important. Although international studies to understand e-HISB among adolescents and adults are rising [18-20], associated motivators and barriers among older adults have not been adequately studied and documented worldwide. In an effort to address the gap, the present study was conducted to examine factors related to e-HISB among older adults in Iran, to improve our understanding of e-health literacy which could have theoretical and practical implications for policymakers and health care providers.

\section{Theoretical Frameworks and Hypotheses}

\section{e-HISB and Older Adults}

Health information-seeking behavior is defined as obtaining information about a healthy lifestyle, alternative medicine, nutrition, and exercise [21]. In addition, eHISB refers to searching, finding, evaluating, and applying health information from various online sources [22]. Theoretical perspectives related to older adults' e-HISB are outlined below.

\section{Health Belief Model}

Older adults may not be able to use the Internet [6, 23 ], and those who can, may lack online search skills [23], which may adversely affect their e-HISB $[6,23]$. According to the Health Belief Model (HBM), an individual's health behavior depends on the existence of certain beliefs toward a given condition [24]. According to the HBM, perceived barriers, defined as a belief about the tangible and psychological costs of a behavior [24], can be a key predictor of health behavior [25]. Several individual, web-based, and economic barriers, namely, loss of vision, cognition, physical impairments that make the use of digital devices difficult, lower levels of education [17], becoming frustrated when learning to use computers and the Internet $[4,7,17]$, lack of confidence, distrust of the Internet, the volume of available information, and inconsistency of information across sources, may restrict older adults' use of the Internet [17, 26]. Additionally, in Iran, a large number of older adults lack the funds to buy computers or other portable devices to access the Internet [27]. Our first hypothesis, $\mathrm{H} 1$, was that older adults' perceived barriers are negatively associated with e-HISB.

\section{Technology Acceptance Model}

Davis et al. [28] proposed the Technology Acceptance Model (TAM), which is used to predict the possibility of accepting and utilizing an information system due to extrinsic and intrinsic motivations. The TAM assumes that intention and actual use of the information system can be predicted by perceived usefulness and ease of use. Perceived usefulness, in the context of the e-HISB, is defined as the degree to which individuals believe that online health information would enhance their performance in managing health conditions [29]. Perceived ease of use is defined as the degree to which individuals believe that the e-HISB would be free of effort. The TAM has been used to inform health information-seeking studies [15, 29], and it is reported that perceived usefulness is a stronger predictor of the intention to seek information than is the perceived ease of use $[15,29]$. Thus, we hypothesized that perceived usefulness of the Internet would be positively associated with e-HISB (H2).

\section{Self-Efficacy Theory}

Bandura [30] theorized that people with high self-efficacy expect to acquire success because of their efforts. Self-efficacy is one's belief in his/her ability to succeed in specific situations or accomplish a behavior [18]. Self-efficacy is known as a core determinant of behavior, provid- 
ing a foundation for human motivation, well-being, and personal accomplishment [31], and Savolainen [32] stated that self-efficacy can be a strong motivational factor in information-seeking behavior. Consequently, we hypothesized a positive correlation between self-efficacy for online information seeking and e-HISB (H3).

\section{Social Support}

Social support is related to the meeting of social needs [33], which has been suggested as an important factor in successful aging [34]. Social support may facilitate healthpromoting behaviors and encourage the achievement of personal goals [35], thus increasing e-HISB [20]. Additionally, the literature suggests that family members can be instrumental in encouraging older adults to take advantage of the Internet in obtaining necessary information [36, 37]. Therefore, our fourth hypothesis, H4, was that perceived encouragement from family and peers has a positive correlation with e-HISB.

\section{Materials and Methods}

\section{Participant Selection}

This cross-sectional study took place from November 2019 to March of 2020 in Tabriz, Iran. The inclusion criteria were (1) being at least 60 years old, (2) able to read and write, (3) being literate in Internet use, and (4) having access to the Internet. The sample size estimation was based on the following parameters: (1) odds ratio $=0.56,(2)$ level of significance $=0.05$, (3) power $=0.80$, and (4) effect size $=1.50$, utilizing G-Power 3.1 (Sheng \& Simpson, 2015), which resulted in 312 (rounded up to 320) as the required number of participants.

We recruited participants from three different settings to reach our sample size of 320 participants. These included (1) Health Care Delivery Centers (HCDC), (2) Civil Servants Pension Organization (CSPO), and (3) city parks as per the inclusion criteria. In recruiting the sample from health centers, we randomly selected four urban regions, and in the next phase, we randomly selected $1 \mathrm{HCDC}$ in each region. Then, among the selected HCDCs, 147 (45.94\%) older individuals referred to receive regular health care services were invited to participate in the study. The second group included 92 (28.75\%) of the retired employees visiting CSPO for various issues. The final category included 81 (25.31\%) visitors of the local city parks who met the study's inclusion criteria. All participants were invited based on the convenience sampling method, and a self-reported survey questionnaire was used for data collection. The study was approved by the Tabriz University of Medical Sciences Ethics Committee, and informed consent was obtained from all participants before completing the survey instrument.

\section{Instrumentation}

The following demographic data were obtained: age, gender, marital status, education level, residency status, employment status, income, financial dependence on spouse or children (yes/no), having health insurance (yes/no), history of current illnesses (yes/ no), suffering from two or more illnesses (yes/no), and history of having had surgery (yes/no).

\section{Health Information-Seeking Behavior}

Health information-seeking behavior is a measure of how actively people look for health information [21], which was measured by 2 questions: Have you ever searched an information source for health information in the last 12 months? (yes/no). If yes, what information sources do you search the most to get the health information you need? (Internet/health care providers/family members or friends/print sources/television and radio). In case of choosing "Internet," the participants were classified as e-HISB and others as non-e-HISB.

Based on a previous study [38], we identified the variables that were used to measure the health information-seeking behavior, namely, (1) self-efficacy for online information seeking, (2) perceived encouragement, (3) positive attitude toward e-HISB, (4) perceived usefulness, (5) challenges of being visited by physicians, and (6) online-seeking inhibitors and perceived barriers to eHISB. A 5-point Likert-type scale $(1=$ strongly disagree; $5=$ strongly agree) was used to measure the motivators and inhibitors of the e-HISB; the negatively stated items were reverse-coded. The information/data obtained from the qualitative component of the study, which consisted of interviewing 19 older adults and reviewing the relevant literature, were used to formulate the items for 4 of the 6 scales; the other 2 scales were derived from published instruments. A panel of experts examined and approved the content validity of the scales. The construct validity of the instrument was investigated, using exploratory factor analysis. A group of older adults pilot tested the utility of the survey instrument. Cronbach's coefficient alpha for all scales was greater than 0.80 , attesting to the internal consistency of the items.

Self-Efficacy for Online Information Seeking

A modified version of the Information Seeking Self-Efficacy Scale (IRSES) [18], which included 7 items, was used to assess selfefficacy. The IRSES has 4 subscales. For the purpose of our study, we used the 7 items of IRSES that were found to be suitable and relevant for our investigation. Two examples of the items are as follows: "I can usually find the information I need on the internet." "If I can't find what I'm looking for, I usually give up." The scale's reliability coefficient was 0.89 .

\section{Perceived Encouragement}

A 9-item scale was developed by the research team to measure perceived encouragement. An example of the items is as follows: "I am interested in using the Internet to search for health information because my family encourages me to practice the e-HISB." The reliability coefficient for the scale was 0.88 .

\section{Positive Attitude toward e-HISB}

This scale included 4 items that were derived from the qualitative component of the study. An example of the items is as follows: "I am interested in using the Internet to seek health information because it has become an important part of life." The reliability coefficient for the scale was 0.88 .

Perceived Usefulness

A 5-item scale developed for this study was used to measure the perceived usefulness to the Internet for health information seeking. 
Table 1. Sample characteristics, $n=320$

\begin{tabular}{|c|c|c|c|}
\hline Variable & $N(\%)$ & Variable & $N(\%)$ \\
\hline Gender & & Education level & \\
\hline Male & $162(50.60)$ & Diploma or lower & $197(61.60)$ \\
\hline Female & $158(49.40)$ & College & $123(38.40)$ \\
\hline Marital status & & Monthly income & \\
\hline Single & $49(15.30)$ & Less than 240 USD & $9(2.90)$ \\
\hline Married & $271(84.70)$ & 241-569 USD & $69(22.10)$ \\
\hline Residency status & & 570-780 USD & $114(36.50)$ \\
\hline Living alone & $29(9.10)$ & More than 780 USD & $45(14.40)$ \\
\hline Living with family & $289(90.30)$ & No income & $75(24.00)$ \\
\hline Employment status & & $\begin{array}{l}\text { Financial dependence on } \\
\text { spouse or children }\end{array}$ & $84(26.30)$ \\
\hline Self-employed & $25(7.90)$ & Having insurance & $292(91.80)$ \\
\hline Retired & $179(56.60)$ & Having prior illness & $239(74.90)$ \\
\hline Housewife & $90(28.50)$ & $\begin{array}{l}\text { Suffering from various } \\
\text { illnesses }\end{array}$ & $88(27.50)$ \\
\hline Office work & $11(3.50)$ & & \\
\hline Laborer & $5(1.60)$ & Having had a surgery & $97(30.30)$ \\
\hline Others & $6(1.90)$ & & \\
\hline
\end{tabular}

Two examples of the items are as follows: "I think using the Internet to seek health information can provide quick access to the information I need." "I think using the Internet to seek health information might waste my money." The scale's reliability coefficient was 0.94 .

Challenges of Being Visited by Physicians

This scale included 14 items and was developed by the research team. Two examples of the items are as follows: "I am interested in using the Internet to search for health information because waiting in the doctor's clinic is boring and hard for me." "I prefer to see my doctor rather than wasting my time on the internet." The reliability coefficient for the scale was 0.87 .

Online Seeking Inhibitors, Perceived Barriers to e-HISB

The Perceived Barriers to the e-Health Information Seeking Psychological scale with 7 items [19] and the Perceived Barriers to the Internet Use scale [17], which included 9 items, were used to assess barriers to e-HISB. We removed duplicate items and measured the following: (1) low e-health literacy, (2) information overload, (3) conflicting information, (4) physical age-related problems, (5) distrust of online information, (6) fear of technology, (7) inadequate design of websites for older adults, and (8) Internet access. Examples of the items are as follows: "I am not fully aware of seeking information through Internet." "I am having suspicion regarding the validity and reliability of the information."The scale's reliability coefficient was 0.83 .

\section{Statistical Analysis}

To analyze the data, we employed the Statistical Package for Social Sciences, version 23, for Windows. The level of significance was set, a priori, at 0.05 . Case-wise deletion was used in handling the missing data. We performed descriptive statistics to summarize and organize the data. To identify the predictors of e-HISB, a series of binary logistic regression analyses were used. Odds ratios were used to examine the practical significance of the findings.

\section{Results}

The majority $(70.00 \%, n=224)$ of the participants were using e-HISB. The participants ranged in age from 60 to 75 years $($ mean $=64.36, \mathrm{SD}=4.41)$. Sample characteristics are presented in Table 1 . The variables used to predict eHISB are summarized in Table 2. A binary logistic regression showed that marital status (married), education level (diploma or lower), monthly income (571-786 USD and more than 786 USD), and history of surgical operations were the statistically significant predictors of eHISB. The second binary logistic regression included the statistically significant demographic characteristics, as well as the possible motivating factors and inhibiting variables. As shown in Table 2, self-efficacy, perceived encouragement, positive attitude toward the e-HISB, perceived usefulness, and challenges of being visited by physicians were statistically significant and increased the odds of e-HISB by $37.00 \%, 22.00 \%, 56.00 \%, 31.00 \%$, and $6.00 \%$, respectively. Conversely, perceived barriers to eHISB reduced the odds by $17.00 \%$. Additionally, after adjusting for the demographic variables, self-efficacy, positive attitude toward the e-HISB, perceived usefulness, and perceived barriers to e-HISB remained statistically significant; specifically, the first 3 increased the odds by $12.00 \%$, $24.00 \%$, and $15.00 \%$, respectively, while perceived barriers reduced the odds by $16.00 \%$. The level of education (diploma or lower) was the only demographic characteristic that remained statistically significant in the adjusted 
Table 2. Demographic characteristics, motivators, and inhibitors of e-HISB

\begin{tabular}{|c|c|c|c|c|c|c|}
\hline Variables & yes $(n=224), n(\%)$ & no $(n=96), n(\%)$ & OR & $p$ value & OR & $p$ value \\
\hline Male & $117(52.20)$ & $45(66.90)$ & Reference & - & - & - \\
\hline Female & $107(47.80)$ & $51(35.10)$ & 0.81 & 0.38 & - & - \\
\hline \multicolumn{7}{|l|}{ Marital status } \\
\hline \multicolumn{7}{|l|}{ Education level } \\
\hline Diploma or lower & $113(50.45)$ & $84(87.50)$ & 1.79 & $<0.05$ & 0.19 & $<0.05$ \\
\hline College & 111 (49.55) & $12(12.50)$ & Reference & - & - & - \\
\hline \multicolumn{7}{|l|}{ Residency status } \\
\hline Living with family & $17(7.70)$ & $12(12.50)$ & 1.72 & 0.17 & - & - \\
\hline Living alone & $205(92.30)$ & $84(87.50)$ & Reference & - & - & - \\
\hline Office work & $9(4.10)$ & $2(2.10)$ & 0.90 & 0.94 & - & - \\
\hline Laborer & $2(0.90)$ & $3(3.20)$ & 0.13 & 0.16 & - & - \\
\hline Others & $5(2.30)$ & $1(1.10)$ & Reference & - & - & - \\
\hline \multicolumn{7}{|l|}{ Monthly income } \\
\hline Less than 238 USD & $5(2.30)$ & $4(4.30)$ & 1.11 & 0.88 & 4.76 & 0.28 \\
\hline $262-548$ USD & $46(20.90)$ & $23(25.00)$ & 1.77 & 0.09 & 8.87 & 0.06 \\
\hline 571-786 USD & $93(42.30)$ & $19(20.70)$ & 4.34 & $<0.05$ & 8.78 & 0.06 \\
\hline More than 786 USD & $36(16.40)$ & $11(12.00)$ & 2.90 & $<0.05$ & 1.50 & 0.74 \\
\hline Without income & $40(18.20)$ & $35(38.00)$ & Reference & - & - & - \\
\hline Financial dependence on spouse or children & $46(20.60)$ & $38(40.00)$ & 0.39 & 0.26 & 3.32 & 0.26 \\
\hline Having insurance & $207(92.40)$ & $85(88.50)$ & 1.78 & 0.16 & - & - \\
\hline Having prior illness & $162(72.30)$ & $76(79.20)$ & 0.69 & 0.22 & - & - \\
\hline Perceived usefulness & $19.92(4.05)$ & $14.21(4.73)$ & 1.31 & $<0.05$ & 1.15 & $<0.05$ \\
\hline Challenges of visiting a doctor & $42.93(9.89)$ & $37.61(10.42)$ & 1.06 & $<0.05$ & 1.01 & 0.67 \\
\hline Perceived barriers to e-HISB & $31.48(7.54)$ & $40.92(6.54)$ & 0.83 & $<0.05$ & 0.84 & $<0.05$ \\
\hline
\end{tabular}

model. The model fit the data $\left(\chi^{2}=9.78, p=0.28\right)$ and correctly classified $92.10 \%$ of the subjects.

\section{Discussion}

The study's findings supported the validity of some demographic and cognitive factors in predicting e-HISB among older Iranian adults. Specifically, perceived usefulness, self-efficacy, and positive attitude toward e-HISB were associated with greater likelihood of e-HISB, and perceived barrier was associated with lower likelihood of e-HISB. Lower education was also associated with lower likelihood of e-HISB.

To address the first hypothesis, we identified low ehealth literacy, information overload, conflicting information, physical age-related problems, distrust of online information, fear of technology, inadequate design of websites for older adults, and Internet access as the major barriers to e-HISB. Our findings are in line with the literature [17, 39-42]. However, most of the participants reported using e-HISB in spite of such barriers. 
According to the TAM, perceived usefulness is an important determinant of accepting new technologies [28]. Perceived usefulness is defined as the belief that using the technology would bring benefits to the user [28], which is also a key predictor of technology use in older adults [43]. In particular, a study of Singaporean seniors demonstrated that perceived usefulness significantly predicted the intention to use an e-service [43]. In the present study, perceived usefulness, which had been hypothesized as an extrinsic motivator (H2), was associated with e-HISB. Extrinsic motivation is defined as performing an activity that is perceived to be instrumental in achieving valued outcomes that are distinct from the activity itself [44]. Furthermore, Lim et al. [15] stated the decision to adopt technology is mostly driven by utilitarian motivations, suggesting that to use the Internet for seeking health information, older adults must first be convinced that e-HISB would be beneficial in enhancing their health. In fact, it is shown that older adults consider the Internet as a valuable tool for accessing the information they need [42]. Moreover, it is documented that obtaining health information through the Internet can increase older adults' positive emotions and satisfaction [45], especially among those who are homebound, live in remote areas, and cannot easily travel [39]. Thus, these useful features of the Internet may be instrumental in persuading older people to use it to acquire information.

Previous studies have documented a positive association between self-efficacy and e-HISB $[13,14]$, which was also supported by our findings regarding the third hypothesis. Self-efficacy, which is considered an essential component of accomplishment and well-being [46], has consistently been identified as an important determinant of health behavior in older adults [47]. In fact, self-efficacy has theoretical and practical implications in enhancing the health status of older adults [48]; that is, people with strong beliefs in their ability to achieve health-related goals are capable of strengthening their efforts to overcome barriers and improve their health condition [49]. Therefore, older people with high self-efficacy are expected to adapt to agerelated changes by seeking health-related information to deal with chronic and multiple diseases.

Older adults' positive attitude toward the e-HISB was another significant predictor of the e-HISB. We live in a digital age, where the Internet has become an integral part of human life, and a large portion of work and communication is done electronically. For the majority of older adults, the Information Communication Technology is new, and they may initially refuse to try it. However, the formation of a positive attitude toward the e-HISB among older adults with the increased popularity of the Internet and understanding its usefulness may be instrumental for e-HISB [50].

\section{Limitations}

Due to the nonprobability nature of the sampling, external validity was limited to the study's participants; thus, a replication of the study with a representative sample is recommended. The cross-sectional study was not experimental; consequently, no causal inferences may be drawn. We assumed that the study participants provided honest answers; nevertheless, giving socially acceptable answers could not be ruled out as a threat to the internal validity of the findings. Moreover, we categorized participants who have used the Internet as the primary source of their required health information as e-HISB. While other participants who were able to use the Internet to seek health information but have not reported it as the main source of health information were considered as non-e-HISB.

\section{Conclusion}

The study's findings supported three of the four theory-driven a priori hypotheses, which could have theoretical and clinical implications. These results suggest that those who work with older adults should focus on the development of programs aimed at enhancing older adults' confidence in e-HISB and the usefulness of the Internet in locating health-relevant information, particularly in the COVID-19 era.

\section{Statement of Ethics}

The Ethics Committee at the Tabriz University of Medical Sciences (Code No. IR. TBZMED.REC.1397.303) approved this study. Informed written consent was obtained from all the participants before completing the survey instrument.

\section{Conflict of Interest Statement}

The authors declare no conflicts of interest.

\section{Funding Sources}

This article is part of a $\mathrm{PhD}$ dissertation in health education and promotion, which was supported and approved by the Tabriz University of Medical Sciences, Tabriz, Iran. The funders had no role in study design, data collection and analysis, decision to publish, or preparation of the manuscript. 


\section{Author Contributions}

Study design: S.P., H.A., and S.H.B. Data collection: S.P. Data analysis: S.P., H.A., and M.A.J. Manuscript writing: S.P., H.A., M.A.J., and M.H. Manuscript editing: K.K. All authors have read and approved the manuscript.

\section{Data Availability Statement}

All data generated or analyzed during this study are included in this article. Further enquiries can be directed to the corresponding author.

\section{References}

1 Cristea M, Noja GG, Stefea P, Sala AL. The Impact of population aging and public health support on EU labor markets. Int J Environ Res Public Health. 2020;17(4):1439.

2 Moat K, Gauvin F-P, Lavis J, editors. Topic overview: sharing health information with older adults through online resources in canada. Hamilton, Canada: McMaster Health Forum; 2014.

3 McGilton KS, Vellani S, Yeung L, Chishtie J, Commisso E, Ploeg J, et al. Identifying and understanding the health and social care needs of older adults with multiple chronic conditions and their caregivers: a scoping review. BMC Geriatr. 2018;18(1):231.

4 Czaja SJ, Charness N, Fisk AD, Hertzog C, Nair SN, Rogers WA, et al. Factors predicting the use of technology: findings from the center for research and education on aging and technology enhancement (CREATE). Psychol Aging. 2006;21(2):333-52.

5 Luger TM, Houston TK, Suls J. Older adult experience of online diagnosis: results from a scenario-based think-aloud protocol. J Med Internet Res. 2014;16(1):e16.

6 Taha J, Sharit J, Czaja S. Use of and satisfaction with sources of health information among older Internet users and nonusers. Gerontologist. 2009;49(5):663-73.

7 Gatto SL, Tak SH. Computer, internet, and Email use among older adults: benefits and barriers. Educ Gerontol. 2008;34(9):800-11.

8 McMillan S, Avery EJ, Macias W. From have nots to watch dogs: understanding internet health communication behaviors of online senior citizens. Inform Commun Soc. 2008; 11(5):675-97.

9 Wagner N, Hassanein K, Head M. Computer use by older adults: amulti-disciplinary review. Comput Hum Behav. 2010;26:870-82.

10 Zhao X, Fan J, Basnyat I, Hu B. Online health information seeking using "\#COVID-19 patient seeking help" on Weibo in Wuhan, China: Descriptive Study. J Med Internet Res. 2020;22(10):e22910.

11 Renahy E, Chauvin P. Internet uses for health information seeking: a literature review. Rev Epidemiol Sante Publique. 2006;54(3):26375.

12 van Uden-Kraan CF, Drossaert CH, Taal E, Seydel ER, van de Laar MA. Participation in online patient support groups endorses patients' empowerment. Patient Educ Couns. 2009;74(1):61-9.
13 Bass SB, Ruzek SB, Gordon TF, Fleisher L, McKeown-Conn N, Moore D. Relationship of internet health information use with patient behavior and self-efficacy: experiences of newly diagnosed cancer patients who contact the national cancer institute's cancer information service. J Health Commun. 2006; 11(2):219-36

14 Lee CJ, Gray SW, Lewis N. Internet use leads cancer patients to be active health care consumers. Patient Educ Couns. 2010;81 Suppl(Suppl 0):S63-9.

15 Lim S, Xue L, Yen CC, Chang L, Chan HC, Tai BC, et al. A study on singaporean women's acceptance of using mobile phones to seek health information. Int J Med Inform. 2011; 80(12):e189-e202.

16 Wang J, Xiu G, Shahzad F. Exploring the determinants of online health informationseeking behavior using a meta-analytic approach. Sustainability. 2019;11(17):4604.

17 Chang J, McAllister C, McCaslin R. Correlates of, and barriers to, internet use among older adults. J Gerontol Soc Work. 2015; 58(1):66-85.

18 Bronstein J. The role of perceived self-efficacy in the information seeking behavior of library and information science students. J Acad Librarianship. 2014;40(2):101-6.

19 Kartiwi M, Munassar F. Assesment of perceived barriers on online health information seeking activites among university students: case study of Malaysia. J Inf Syst Digital Tech. 2019;1(1).

20 McKinley CJ, Wright PJ. Informational social support and online health information seeking: examining the association between factors contributing to healthy eating behavior. Comput Hum Behav. 2014;37:107-16.

21 Niederdeppe J, Hornik RC, Kelly BJ, Frosch DL, Romantan A, Stevens RS, et al. Examining the dimensions of cancer-related information seeking and scanning behavior. Health Commun. 2007;22(2):153-67.

22 Zuckerman M. Online health information seeking behaviors among college undergraduates. Baltimor Country: University of Maryland; 2009

23 Fox S. Online health search. Washington DC: Pew Internet \& American Life Project; 2006.

24 Glanz K, Rimer BK, Viswanath K. Health behavior and health education: theory, research, and practice. 4th ed. Jossey-Bass publisher; 2008 .
25 Carpenter CJ. A meta-analysis of the effectiveness of health belief model variables in predicting behavior. Health Commun. 2010; 25:661-9.

26 Lee K, Hoti K, Hughes JD, Emmerton L. Dr google is here to stay but health care professionals are still valued: an analysis of health care consumers' internet navigation support preferences. J Med Internet Res. 2017;19(6): e210.

27 Momeni M, Hariri N, Nobahar M, Noshinfard F. Barriers and challenges experienced by seniors in using online social networks: a phenomenological study. Middle East J Rehabil Health Stud. 2018;5(1):e65310.

28 Davis FD, Bagozzi RP, Warshaw PR. User acceptance of computer technology: a comparison of two theoretical models. Manage Sci. 1989;35(85):982-1003.

29 Liang H, Xue Y, Chase SK. Online health information seeking by people with physical disabilities due to neurological conditions. Int J Med Inform. 2011;80(11):745-53.

30 Bandura A. Self-efficacy. Encyclopedia of human behavior V.S. Ramachaudran. New York: Academic Press; 1994. p. 71-81.

31 Pajares F. Gender and perceived self-efficacy in self-regulated learning. Theor Into Pract. 2002;41(2):116-25.

32 Savolainen R. Elaborating the motivational attributes of information need and uncertainty. Inf Res. 2012;17(2):516.

33 Miller CA. Nursing for wellness in older adults. Philadelphia, PA: Wolters Kluwer Health/Lippincott Williams \& Wilkins; 2009.

34 Gallagher LP, Truglio-Londrigan M. Community support: older adults' perceptions. Clin Nurs Res. 2004;13(1):3-32.

35 Kwong E-Y., Kwan A-H. Stress management methods of the community dwelling elderly in Hong Kong: Implications for tailoring a stress-reduction program. Geriatr Nurs. 2004;25(2):102-6.

36 Johnson RD, Hornik S, Salas E. An empirical examination of factors contributing to the creation of successful e-learning environments. Int J Human-Computer Stud. 2008; 66(5):356-69.

37 Selwyn N. The information aged: a qualitative study of older adults' use of information and communications technology. J Aging Stud. 2004;18(4):369-84. 
38 Pourrazavi S, Hashemiparast M, BazarganHejazi S, Ullah S, Allahverdipour H. Why older people seek health information online: a qualitative study. Adv Gerontol. 2021;11(3): 290-7.

39 Becker SA. A study of web usability for older adults seeking online health resources. ACM Trans Comput Hum Interact. 2004;11(4): 387-406.

40 Carpenter BD, Buday S. Computer use among older adults in a naturally occurring retirement community. Comput Hum Behav. 2007; 23(6):3012-24

41 Fisk AD, Czaja SJ, RogersWA, CharnessN, Sharit J. Designing for older adults. 2nd ed. Boca Raton, FL: CRC Press; 2009.

42 Miller LM, Bell RA. Online health information seeking: the influence of age, information trustworthiness, and search challenges. J Aging Health. 2012;24(3):525-41.
43 Phang CW, Li Y, Sutanto J, Kankanhalli A. Senior citizens' adoption of e-government: in quest of the antecedents of perceived usefulness. Proceedings of the 38th Annual Hawaii International Conference on System Sciences. Big Island, HI, USA: IEEE; 2005.

44 Ajuwon GA, Popoola SO. Influence of motivational factors on utilisation of internet health information resources by resident doctors in Nig

eria. Electron Libr. 2015;33(1):103-19.

45 Botella C, Etchemendy E, Castilla D, Baños RM, García-Palacios A, Quero S, et al. An ehealth system for the elderly (butler project): a pilot study on acceptance and satisfaction. Cyberpsychol Behav. 2009;12:255-62.

46 Bandura A. Self-efficacy: the exercise of control. New York: Freeman \&CompanyW.H; 1997.

47 Eriksson-Backa K, Enwald H, Hirvonen N, Huvila I. Health information seeking, beliefs about abilities, and health behaviour among Finnish seniors. J Libr Inf Sci. 2018;50(3): 284-95.
48 Grembowski D, Patrick D, Diehr P, Durham M, Beresford S, Kay E, et al. Self-efficacy and health behavior among older adults. J Health Soc Behav. 1993;34(2):89-104.

49 Oh YS. Predictors of online health information seeking behavior and health information seeking experience of elderly cancer survivors using the internet, in school of graduate studies. Case Western Reserve University; 2016.

50 Zhang J, Umemuro H. When older adults start and stop to use technologies: long term study on technology usage, computer attitudes and cognitive abilities of Japanese older adults, in ISG*ISARC2012 Full Paper Proceedings. Netherlands: International Association for Automation and Robotics in Construction (IAARC); 2012. 